\title{
E-Commerce Logistics Mode Selection Based on Network Construction
}

\author{
Hanlin Qian \\ School of Business Administration, South China University of Technology, Guangzhou, China \\ Email: scutqian@126.com
}

How to cite this paper: Qian, H.L. (2019) E-Commerce Logistics Mode Selection Based on Network Construction. Modern Economy, 10, 198-208.

https://doi.org/10.4236/me.2019.101014

Received: December 28, 2018

Accepted: January 15, 2019

Published: January 18, 2019

Copyright $\odot 2019$ by author(s) and Scientific Research Publishing Inc. This work is licensed under the Creative Commons Attribution International License (CC BY 4.0)

http://creativecommons.org/licenses/by/4.0/

\section{(c) (i) Open Access}

\begin{abstract}
The article studies the selection of logistics mode for e-commerce enterprises. Firstly we give a general introduction to the development of China's e-commerce logistics and existing logistics models. According to the principles established by the literature, the corresponding indicator system for the decision-making of the e-commerce enterprise logistics model is established, and four first-level indicators are given: commodity attributes, service levels, enterprise capabilities and total costs. The weight of the indicator is established by means of analytic hierarchy process. Through the case of Jingdong, the application and testing of the indicator system will be carried out, and the indicator system will be evaluated. The main contribution of the article is to propose a more comprehensive and scientific decision-making indicator system, and through the use of the analytic hierarchy process, the weight comparison between the indicators is given, which greatly simplifies the use cost of the enterprise and makes the method more practical.
\end{abstract}

\section{Keywords}

E-Commerce Logistics, Self-Built Logistics, Outsourcing Logistics, Decision-Making Indicator System

\section{Introduction}

E-commerce logistics is a series of logistics activities derived from e-commerce demand. It has the characteristics of strong timeliness, wide service space and long supply chain. According to the year-on-year indicator from E-commerce Public Service Alliance ${ }^{1}$, the 2016 total business volume indicator reached an average of 156.1 points, reflecting the growth rate of e-commerce logistics business volume over $50 \%$. If we use the total volume in 2015 as the benchmark indicator, ${ }^{1} 2016$ E-commerce Logistics Operation Analysis and 2017 Outlook Report. 
the benchmark indicator shows that with the base period of 100 points in January 2015, the 2015-2016 total business volume indicator has shown a rapid growth trend, reaching 228.1 points in December 2016, reflecting the growth in total business after two years of growth. The base period is more than twice.

At present, the solution to the problem of China's e-commerce logistics is mainly selected from three modes: self-operated logistics, third-party logistics and logistics alliance. Self-operated logistics refers to the logistics activities that enterprises organize themselves by means of their own material conditions (including logistics facilities, equipment and management institutions). Third-party logistics, also known as outsourcing logistics, is commissioned to entrust some or all of its logistics activities to professional logistics companies within a certain period of time. Logistics alliance refers to the long-term cooperation between two or more enterprises or organizations in the form of contracts to achieve certain logistics goals. Because the establishment of logistics alliance involves many parties' negotiation and game, this paper only focuses on the choice between e-commerce enterprises in self-built logistics and outsourcing logistics to maximize their own interests.

Many experts and scholars have given their opinions on the decision-making problem of e-commerce enterprise logistics mode selection. When researching the relationship between logistics outsourcing and corporate performance, Sink [1] found that the trend of modern business is to outsource non-core business and concentrate on developing core business, outsourcing logistics services to third-party logistics companies. Deborah Bells [2], after studying the logistics distribution model of e-commerce enterprises, believes that there are two kinds of logistics distribution modes: self-operated logistics mode and third-party logistics mode. Qiu [3] proposed the concept of eight logistics models for e-commerce logistics. After comparing the current $\mathrm{B} 2 \mathrm{C}$ e-commerce logistics distribution model, Bao [4] proposed a logistics distribution plan for B2C e-commerce, established a third-party logistics platform, and utilized postal logistics and other distribution resources to promote alliance and resource sharing in the logistics industry and strong enterprise development, self-built logistics and so on.

$\mathrm{Xu}$ [5] established the 21 indicators of B2C e-commerce logistics service quality evaluation indicator system based on the SERVQUAL model and the LSQ model. Zhao [6] believes that e-commerce companies can compare and analyze logistics costs, capital recovery, transportation speed, customer trust, and coverage when choosing a logistics model. Li [7] believes that when e-commerce companies choose logistics models, they should consider four factors: the scale and strength of e-commerce enterprises, the logistics management capabilities and network resources of e-commerce enterprises, the logistics costs and expenses of e-commerce enterprises, and enterprises competitiveness of logistics services. Wu [8] considered the six main influencing factors of logistics importance, enterprise scale strength, total cost, logistics operation capability, logistics information technology and customer service capability. Zhu [9] explores the choice of e-commerce logistics model through AHP method. The author thinks 
that all forms, capital, cost, income and customer satisfaction of e-commerce goods are the main influencing factors when selecting the influencing factors of e-commerce logistics model. Yuan [10], while combining many foreign research results, established four dimensions of evaluation system for cost and investment, customer service, additional services and risk and uncertainty.

The content of the article is divided into three parts. The first is the establishment of a decision-making indicator system, using the literature method to establish an indicator system for the decision-making of e-commerce enterprise logistics mode. Secondly, the establishment of indicator weights, using the analytic hierarchy process, for the difference in the relative importance of different indicators in the evaluation system, gives the ordering of indicator weights. Finally, for the application of the method, taking Jingdong as an example, the applicability of the analytic hierarchy process and the existing evaluation indicator system to the actual situation is given.

\section{Establishment of Decision Indicator System}

\subsection{Choices of Decision Indicators}

According to related work [3] [4] [5] [6] [7], we choose important indicators form their system respectively, establish the following decision indicator system depicted in Table 1.

In Table 1, we choose four essential indicators as Primary Indicator (PI),

Table 1. Decision indicator system.

\begin{tabular}{cc}
\hline Primary Indicator & Secondary Indicator \\
\hline CommodityAttributes $A$ & Product's own value $A_{1}$ \\
Product ownership $A_{2}$ \\
Market range $A_{3}$ \\
\hline Timeliness $B_{1}$ \\
Accuracy $B_{2}$ \\
Visibility $B_{3}$ \\
Breakage rate $B_{4}$ \\
Service attitude $B_{5}$ \\
Reverse logistics $B_{6}$ \\
Enterprise Capabilities $C$ \\
Enterprise size $C_{1}$ \\
Information technology $C_{2}$ \\
Management level $C_{3}$ \\
Growth $C_{4}$ \\
\hline
\end{tabular}

Fixed asset investment cost $D_{1}$

Total Costs $D$

Transportation cost $D_{2}$

Warehousing cost $D_{3}$

Management cost $D_{4}$ 
which includes commodity attributes, service levels, enterprise capabilities, and total costs. These four primary indicators cover different parts of factors in the decision making process when a company tries to select its own logistic mode. In addition, there are different Secondary Indicator (SI) in PI. We can see their name in Table 1, and the explanation of SI is displayed in Section 2.2.

\subsection{Interpretation of Decision Indicators}

The entire decision-making indicator system has four first-level indicators, namely four dimensions: commodity attributes, service levels, enterprise capabilities, and total costs.

Commodity attribute is an objective condition for enterprise decision-making, and it is an attribute that must be satisfied by the e-commerce enterprise's logistics system. There are three secondary indicators: the value of the commodity itself, the ownership of the commodity, and the market scope. The value of the main products operated by e-commerce companies is different, and different enterprises are different. The ownership of goods will be different according to the nature of the e-commerce enterprise, which will cause the corresponding e-commerce enterprises to make different decisions when making logistics solutions. The market scope refers to where the customers of consumer goods are mainly concentrated, which will largely affect the logistics decisions of e-commerce companies.

The service level is the goal that e-commerce enterprises must achieve to establish a logistics system, and is the main source of enterprise competitiveness. The following are six secondary indicators: timeliness, accuracy, visibility, breakage rate, service attitude, and reverse logistics. Timeliness requires logistics speed to be fast enough, accuracy requires logistics and delivery cannot be wrong, visibility means that customers and e-commerce companies must be able to track orders, breakage rate refers to when the package is delivered to the customer, the outer packaging and the internal must be complete. Service attitude means that the attitude of the service personnel who are in direct contact with the customer must be good. Reverse logistics refers to whether the e-commerce enterprise can respond positively and promptly when the customer has the requirement to return the goods.

There are four secondary indicators under enterprise capabilities: firm size, information technology, management level and growth. The size of the enterprise is the embodiment of the company's current overall capabilities. Information technology is the ability of enterprises to manage their own logistics assets and logistics systems with low cost and high efficiency. The management operation level is reflected in the professional knowledge and experience of the management personnel, and also in the management process of the enterprise. Growth can measure the prospects of the company's own business.

The total cost measures the price a company must pay. There are four secondary indicators under total cost: fixed asset cost, transportation cost, storage 
cost, and management cost. Fixed cost is the investment of fixed assets when enterprises choose to build their own logistics or outsource logistics. Transportation costs refer to the cost of goods transport. The storage cost is the cost of the company's goods, the cost of stocking, and so on. The management cost mainly refers to the salary of the management personnel and the corresponding depreciation expenses.

With the indicator system, the following is to establish the weight of the indicators, sort the indicators according to the degree of importance, and determine the order in which the enterprises consider the decisions.

\section{Establishment of Weights of Decision Indicators}

The analytic hierarchy process is used to compare the different indicators in the decision-making indicator system, and give their respective weights to facilitate the decision-making of e-commerce enterprises. First, the secondary indicators below each primary indicator are sorted, and then the weights of the four primary indicators are set.

\subsection{Application of Analytic Hierarchy Process}

Because the decision at this time only involves the target layer (the logistics model decision of the e-commerce enterprise) and the indicator layer, the purpose is to sort the indicators, and does not involve the specific selection problem of the solution layer, so we describe this process in Figure 1, the single-level hierarchical analysis model can be used.

- Constructing Judgment Matrix

Compare each of the two indicators, and use the target layer as a criterion to determine the relationship between the indicators and construct a judgment matrix. Where $a_{i j}$ represents the numerical representation of the importance of the indicator $A_{i}$ relative to the indicator $A_{j}, a_{i j}$ usually takes $1,3,5,7,9$ and their reciprocals, and a larger number indicates a higher degree of importance.

- Calculate Relative Importance

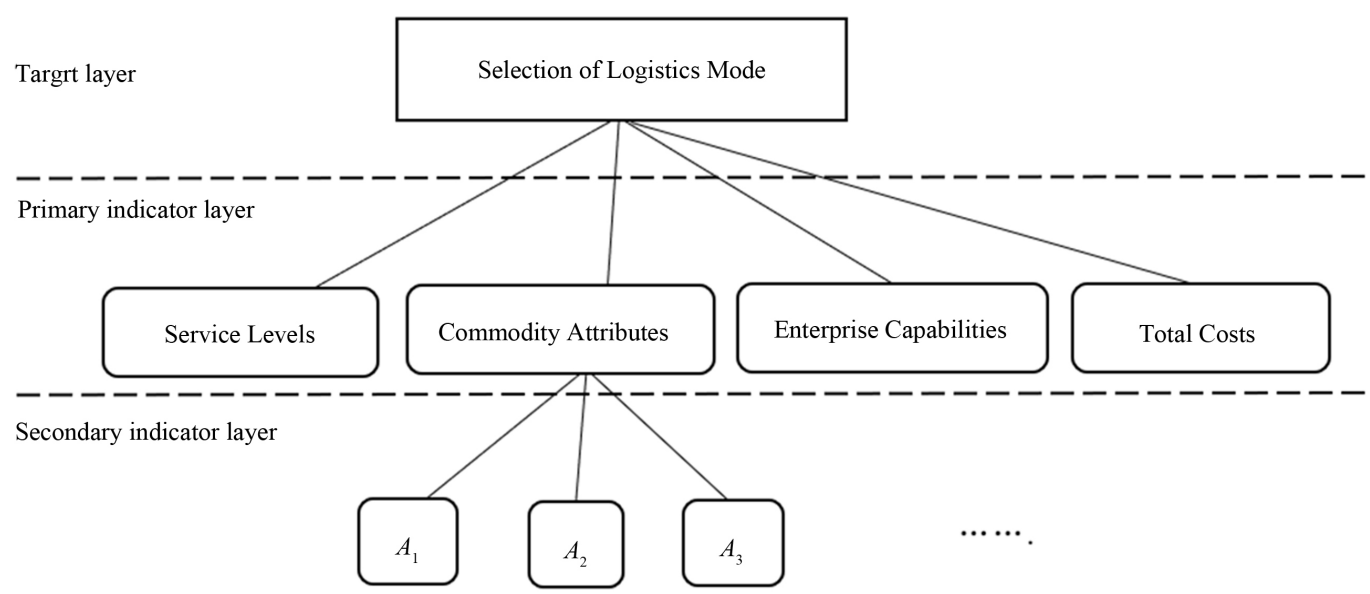

Figure 1. Single-level hierarchical analysis model. 
According to the judgment matrix, the weight of the relative importance order of each indicator for the target element is calculated. Calculate the maximum eigenvalue $\lambda_{\max }$ of the judgment matrix $A$ and the eigenvector $W$ after normalization according to Equation (1).

$$
W=\left[\omega_{1}, \omega_{2}, \ldots, \omega_{k}\right]^{T}
$$

- Consistency Test

First, we must calculate the consistency indicator: C.I. Calculate the average random consistency indicator R.I. It is obtained by repeatedly calculating the number of eigenvalues of the random judgment matrix and taking the arithmetic mean. Calculate the ratio of the two, that is, the consistency ratio: C.R. When C.R. is less than 0.1 , the consistency of the judgment matrix is considered acceptable.

\subsection{The Establishment of Indicator Weights}

Since the weighting between the secondary indicators under each primary indicator is the same as the weighting between the primary ones, the secondary indicators under the service level with the most decision-making indicators are selected as an example.

- Constructing Judgment Matrix

For the first-level indicators of service level, consider six secondary indicators: timeliness, accuracy, visibility, damage rate, service attitude and the relative importance of reverse logistics, and score them. The scores are obtained by reference and related experts. The results are given in Table 2. The numbers in the matrix measure the relative importance between different indicators. We take 1 , $3,5,7,9$ and their reciprocals to represent the degree of importance. For example, the number " 3 " in the second row and the third column, means that the indicator "B1" is much more important than the indicator "B2".

- Calculate Relative Importance

According to the judgment matrix, the results are given in Equation (2).

$$
\begin{gathered}
\lambda_{\max }=6.55 \\
W=\left[\omega_{1}, \omega_{2}, \ldots, \omega_{6}\right]^{T}=[0.403,0.128,0.089,0.103,0.201,0.036]^{T}
\end{gathered}
$$

- Consistency Test

Calculated according to the formula, we can get the results in Equation (3).

$$
\begin{aligned}
& \text { C.I. }=\frac{\lambda_{\max }-k}{k-1}=\frac{6.55-6}{6-1}=0.11 \\
& \text { C.R. }=\frac{\text { C.I. }}{\text { R.I. }}=\frac{0.11}{1.26}=0.087<0.1
\end{aligned}
$$

Thus, the test passed.

\subsection{Calculation Results of Indicator Weight}

After finishing the calculation, the results are given in Table 3. The three attributes 
Table 2. Score matrix.

\begin{tabular}{ccccccc}
\hline$B$ & $B_{1}$ & $B_{2}$ & $B_{3}$ & $B_{4}$ & $B_{5}$ & $B_{6}$ \\
\hline$B_{1}$ & 1 & 3 & 5 & 5 & 3 & 7 \\
$B_{2}$ & $1 / 3$ & 1 & 3 & 3 & 1 & 3 \\
$B_{3}$ & $1 / 5$ & $1 / 3$ & 1 & $1 / 3$ & $1 / 5$ & 1 \\
$B_{4}$ & $1 / 5$ & $1 / 3$ & 3 & 1 & $1 / 3$ & 3 \\
$B_{5}$ & $1 / 3$ & 1 & 5 & 3 & 1 & 5 \\
$B_{6}$ & $1 / 7$ & $1 / 3$ & 1 & $1 / 3$ & $1 / 5$ & 1 \\
\hline
\end{tabular}

Table 3. Calculation results of indicator weight.

\begin{tabular}{|c|c|c|c|}
\hline Results & Eigenvalues & Feature Vector & Consistency Test \\
\hline Commodity Attributes & 3.08 & {$\left[\begin{array}{llll}0.369 & 0.299 & 0.332\end{array}\right]^{T}$} & 0.077 \\
\hline Service Levels & 6.55 & {$\left[\begin{array}{llllll}0.403 & 0.128 & 0.089 & 0.103 & 0.201 & 0.036\end{array}\right]^{T}$} & 0.087 \\
\hline Enterprise Capabilities & 4.24 & {$\left[\begin{array}{llll}0.429 & 0.091 & 0.283 & 0.197\end{array}\right]^{T}$} & 0.091 \\
\hline Total Costs & 4.16 & {$\left[\begin{array}{lllll}0.408 & 0.172 & 0.310 & 0.110\end{array}\right]^{T}$} & 0.058 \\
\hline Logistics Modes & 4.13 & {$\left[\begin{array}{llll}0.283 & 0.211 & 0.308 & 0.198\end{array}\right]^{T}$} & 0.082 \\
\hline
\end{tabular}

in Table 3, which are called "Eigenvalues", "Feature Vector" and "Consistency Test", represent the computing results using Equation (2) and Equation (3). Especially in the fourth column "Consistency Test", we can see the final results: $0.077,0.087,0.091,0.058$ and 0.082 , which are all less than the reference value 0.1 , meaning that the consistency test is passed and the results in Table 3 are valid.

Express the above results as an order between the indicators, depicted in $\mathrm{Ta}$ ble 4.

\subsection{Interpretation of the Results}

For commodity attributes, although the three indicators have different weights, the results are very close: $0.369,0.299,0.332$. In the decision-making process, the value of the commodity and the distribution of the customer are difficult to make qualitative changes in a short period of time, and the two are more important. For the ownership of goods, it is feasible for e-commerce companies to develop another kind of ownership outside their own special projects, and it is also common in actual situations. For example, there are also third-party products in Jingdong. Tmall will also have self-operated products. This indicator is relatively easy to change, so it is of the least importance. But the difference between the three indicators is not that big, because whether it is to develop new types of goods, to open up new customer markets or to attract sellers of different attributes, it is necessary to pay no lower costs and the results are more difficult to predict.

For the service level, timeliness is the most important, and the weight of 0.403 
Table 4. Ordered results of indicators.

\begin{tabular}{cc}
\hline Commodity Attributes & Product's own value $>$ Market range $>$ Product ownership \\
Service Levels & Timeliness $>$ Service attitude $>$ \\
Enterprise Capabilities & Enterprise size $>$ Management level $>$ Growth $>$ Information technology \\
Total Costs & Fixed assets investment cost $>$ Warehousing cost $>$ \\
Transportation cost $>$ Management cost
\end{tabular}

is much larger than other indicators. In real life, the customer feels the strongest and the customer first considers the speed of delivery. In fact, it is a service attitude, because it involves direct contact with customers, which will affect the customer's evaluation of the corresponding company, and once this impression is established, it is difficult to destroy, but it is very easy to destroy. The least important indicators are visibility and reverse logistics. Only when e-commerce companies and competitors' logistics competitiveness are basically the same, e-commerce companies with these two factors will take advantage.

For enterprise capabilities, the size of the enterprise is the most important, followed by management operations and growth, and finally information technology. The weight of the enterprise scale reaches 0.429 , which is close to half, which is far more important than other indicators. This is mainly because the size of the enterprise has a decisive influence on the logistics model and largely determines the development space of the corresponding logistics model, and it is difficult to change in a short time. The second level of management operation is also largely the experience and accumulation of the company, and it is also difficult to replicate. The measurement of growth potential is difficult, which weakens the weight of this indicator to a certain extent. The last information technology can be obtained through purchase, so the weight is the lowest.

For total cost, the corresponding ranking is fixed asset investment cost, storage cost, transportation cost and management cost, which can be explained by the proportion of various costs to total cost. Obviously, the decision to build a self-built logistics is a decision on heavy assets, and the investment in fixed costs is very high. For the same reason, the impact of storage costs is second. The proportion of transportation costs and management costs to total costs decreases in turn, so the importance of indicators is also reduced.

For the choice of logistics mode, the weights of the four primary indicators of commodity attributes, service levels, enterprise capabilities and total costs are $0.283,0.211,0.308,0.198$, respectively. It can be seen that each indicator is important, both in 0.2 or 0.3 , and the values are not much different, which shows that for e-commerce companies, when making the decision of logistics mode, four indicators are very important. Among them, commodity attributes and enterprise capabilities are relatively important, but the gap between the two is small; the service level and total cost are relatively minor, and the gap between 
the two is small. This is also an explanation. For e-commerce companies, commodity attributes and enterprise capabilities are relatively stable, and e-commerce companies must make decisions within their prescribed frameworks, so they are relatively important. Service levels and total costs are relatively flexible. The service level is the goal set by the e-commerce enterprise, and can be adjusted according to its own situation; the total cost is different according to the decision of the enterprise. Even if the self-built logistics is also selected, the enterprise will have different solutions to realize its own. Purpose, so the relative cost of the business can be chosen by itself. Therefore, the importance of the two indicators of service level and total cost is relatively minor.

With the weight of the indicators, we will go back and interpret the four first-level indicators to find the internal logic of the four types of indicators. Commodity attributes and enterprise capabilities are the current state of the enterprise, and are the objective limitations of the enterprise. The commodity attributes are more externally restricted, and the enterprise capacity is more inherently limited. Service level and total cost are the future of the enterprise, that is, the goal of the enterprise. The service level is more at the profit-taking perspective of the enterprise, and the total cost is more considered from the perspective of enterprise cost. Therefore, the four indicators have internal logic, and the analysis of the AHP can also determine the scientific nature of the establishment of the decision indicator system.

\section{Discussion}

The index system of this paper selects four dimensions: commodity attributes, enterprise capabilities, service levels, and total costs. The four dimensions represent the four conditions that decision-making must consider: external constraints, internal constraints, target profits, and target costs. The four indicators comprehensively and scientifically summarize the various situations of decision-making. The first two indicators represent current and objective conditions, and the latter two indicators characterize the future and the purpose of decision making.

E-commerce has flourished in recent years, greatly facilitating people's lives. With the prevalence of online shopping, the corresponding e-commerce logistics has a very broad development space. Whether it is Jingdong, Alibaba, Amazon, Vipshop or SF Group, they will focus on e-commerce logistics. And for a large number of small and medium-sized e+-commerce companies, the logistics and distribution problem is also the most difficult problem. Whether it is to choose self-built logistics or outsourced logistics, e-commerce companies need to make reasonable and prudent decisions according to their own circumstances and the external environment.

Decision makers can make decision analysis based on the AHP method shown in this article, or they can perform quantitative analysis. For managers who lack professional knowledge of decision-making, they can make qualitative decisions 
on the company's situation and make decisions based on the simplified decision-making indicator system. This greatly simplifies the time spent on decision making and also guarantees a high rate of accuracy.

Most of the previous studies have explained the indicators that should be considered in decision-making. Many of them analyze the indicators and obtain the second-level indicators and even the third-level indicators. Although the system is complete, it is slightly bloated and lacks the process of index weighting. In this paper, according to the analytic hierarchy process, the first-level indicators and the second-level indicators under different first-level indicators are sorted. The results are more intuitive. What to consider first when making decisions, what to consider, and what is more important, at a glance.

Compared with the previous five general indicators, the results of this paper are more concise. The results of this paper are not only applicable to general e-commerce companies, such as Jingdong, Vipshop, etc., and because of the simplicity and applicability of the indicators, the same applies to supply chain service companies such as SF Express to make relevant decisions, but possible indicators. The relevant weights will change appropriately.

The practical enhancement of this paper is reflected in two aspects: First, the simplified decision-making index system is obtained according to the results of the analytic hierarchy process. The number of indicators is simplified, and the weights are sorted to facilitate decision-makers to conduct qualitative and quantitative analysis. This is the previous one. What the Institute does not have, has a relatively strong practical value; the second is to facilitate the use of various decision makers. Whether it is the decision-makers with professional knowledge using the analytic hierarchy process for analysis, or the general decision-makers based on experience and qualitative considerations, whether it is an e-commerce enterprise or a supply chain service enterprise, it can be analyzed according to the decision-making index system of this paper, and the practicality is greatly improved.

\section{Conclusions}

The article studies the selection of logistics mode for e-commerce enterprises, establishes the corresponding indicator system for the decision-making of the e-commerce enterprise logistics model, gives four first-level indicators: commodity attributes, service levels, enterprise capabilities and total costs, and gives the corresponding secondary indicators under the first-level indicators. The explanation of the corresponding indicators is given: the commodity attribute indicates the external restriction of the enterprise, and the enterprise capability indicates the internal limitation of the enterprise. The two are relatively more important because it is difficult to change in a short time; the service level represents the target income of the enterprise, and the total cost represents the goal of the enterprise cost, both of which are relatively minor because the company can control them. 
Although the results of this paper have made a lot of progress compared to previous studies, there are also many flaws, which are mainly reflected in two aspects: First, the subjectivity is relatively strong; the selection and scoring of indicators are subjective and relatively strong processes; it is difficult to find objective criteria. At the same time, the analytic hierarchy process is also a relatively subjective method. Even if there is a consistency test, it is easy to bring in personal preference information. The second is being not sensitive to time. The choice of indicators is relatively static. In particular, the logistics plan is a relatively large-scale investment. Even if the situation changes after the decision, the value of the indicator has changed and the logistics plan changes, it is difficult to make timely adjustments.

The main contribution of the article is to propose a more comprehensive and scientific decision-making index system, give the weight ordering between indicators, and simplify the index system to facilitate decision-making by various managers and e-commerce companies.

\section{Conflicts of Interest}

The author declares no conflicts of interest regarding the publication of this paper.

\section{References}

[1] Sink, H.L. and Langley, C.J. (1997) A Managerial Framework for the Acquisition of Third-Party Logistics Service. Journal of Business Logistics, 18, 163.

[2] Bells, D. (2004) E-Commerce Logistics and Implementation. Supply Chain Management. An International Journal, 9, 30-42.

[3] Qiu, D. (2001) Research on the Eight Patterns of Logistics in E-Commerce. China Business and Market, 3, 4-6.

[4] Bao, L., Zhang, Y. and Li, W. (2013) The "Bottleneck" Problem of Logistics Distribution in China's B2C E-Commerce and its Countermeasures. Market Modernization, 103, 103-105.

[5] Xu, N. (2017) Research on B2C E-Commerce Logistics Service Quality Evaluation. International Review of Retail, Distribution and Consumer Research, 13, 161-174.

[6] Zhao, M. and Wang, T. (2017) Research on the Choice of B2C E-Commerce Logistics Mode. China Business, 39, 27-28.

[7] Li, W. (2018) Study on Factors in Selecting Logistics Mode in E-commerce in China. Logistics Technology, 31, 48-49.

[8] Wu, Y. (2017) Study on Selection of Optimal B2C E-Commerce Logistics Mode Based on Fuzzy AHP: In the Case of Dangdang.com. Logistics Technology, 9, 241-243.

[9] Zhu, L. (2014) Research on B2C E-Commerce Logistics Mode Selection Based on AHP: In the Case of Tmall and Jingdong. Commercial Times, 31, 58-61.

[10] Yuan, S. (2017) B2C E-Commerce Delivery: The Research on the Decision Factors of In-House and Outsourcing Logistics within Delivery Model. Journal of Qiqihar University, 32, 84-90. 